\title{
REKONSTRUKTIONEN AF HOPI-INDIANERNES RELIGION, KULTUR OG MENTALITET
}

\author{
Videnskab kontra litteratur
}

Armin W. Geertz

\begin{abstract}
ENGLISH ABSTRACT: "The Reconstruction of Hopi Indian Religion, Culture and Mentality: Science versus Literature" - As 'primitivism' is rampant in anthropological, literary and comparative religion studies of Indians, so have ethnic and religious agendas weakened the academic accountability of postmodern and postcolonial critics, despite all legitimate scientific and social criticisms. In this paper, I appeal to a 'no nonsense' approach to religion, which I have termed 'ethnohermeneutics'. The paper documents my own wayfaring from a historical cultural relativist to social critic and universalist. The latter is mainly a result of breakthroughs in the cognitive and neurobiological sciences. Our discipline is caught in a matrix of relativistic particularism versus common human universals. It cannot be otherwise, if we wish to take seriously the scientific ideal of identifying the origins, forms, functions, structures and meanings of our subject.
\end{abstract}

DANSK RESUME: Mange antropologiske, litteraturvidenskabelige og religionsvidenskabelige indianerstudier hjemsøges af primitivisme-romantik, og megen postmoderne og postkolonial litteratur svakkes af religiøse og etniske dagsordener, trods al berettiget fag- og samfundskritik. Jeg appellerer derfor til en 'no nonsense' tilgang til religion, en tilgang som jeg sammenfatter i begrebet etnohermeneutik. Bidraget dokumenterer min egen vandring fra religionshistorisk kulturrelativist til samfundskritiker og universalist, sidstnoevnte i kraft af erkendelser inden for den kognitive og neurobiologiske forskning. Faget ligger midt $i$ spcendingsfeltet mellem kulturrelativistisk partikularisme og almen menneskelig universalisme. Det kan ikke vare anderledes, hvis vi skal leve op til et fag, der tager sit genstands oprindelser, former, funktioner, strukturer og betydninger alvorligt.

KEYWORDS: Religion, Culture, Mentality, Hopi, Reconstruction, Primitivism, Hermeneutics, Theory, Method

Tanken med dette bidrag er at give et aktuelt og meget konkret eksempel på to forskellige tilgange til rekonstruktion af kulturer. Flere af de problemstillinger, der i andre af dette temanummers artikler drøftes i et mere teoretisk perspektiv, dokumenteres her gennem et eksempel hentet fra mit eget feltarbejde. Jeg vil vise, hvor galt det kan gå, når man rekonstruerer en fremmed kultur ud fra egne, uigennemskuede fordomme. 
Samtidig vil jeg med eksemplet forsøge at skitsere en metodisk farbar vej for rekonstruktion af kulturer. Som en af ophavsmændene bag Religionsvidenskabelig Tidsskrift har bidraget også givet mig anledning til at se på min egen forskningsodysse gennem de forgangne 25 år i relation til rekonstruktionsspørgsmålet.

I november 2002 modtog Vagn Lundbye Det Danske Akademis store pris. Han redegjorde i sin takketale, der blev trykt i Weekendavisen (Lundbye 2002), for Einsteins relativitetsteori, der viser, at "tid og rum ikke er to uafhængige størrelser, men tværtimod er knyttet sammen i en firedimenional struktur, en 'rumtid'." Han bedyrer oven i købet, at hvis man rejser til et ormehul ude i rummet, kan man nå frem eller tilbage til forhistoriske begivenheder. Det glæder mig, at vi er nået dertil. Jeg vil selv gerne finde ud af, hvordan Homo sapiens er opstået og hvorfor de fandt på religion. Når jeg imidlertid fremdrager eksemplet, skyldes det hans efterfølgende påstande:

\begin{abstract}
Det interessante i den forbindelse, jeg står i her, er, at hopiindianerne i Arizona altid har opereret med rumtid, og i alt væsentligt har opfattet tid på en måde, som mere har med Einstein end Newton at gøre... I 1974 boede jeg hos hopiindianerne i Arizona, og opdagede da det besynderlige, at hopierne i deres sprog ingen ord eller grammatiske former har for det, som vi europæere kalder tid. Der findes med andre ord ingen mulighed for at opdele tid i fortid, nutid og fremtid. Ved hjælp af helt andre og meget mere intense strukturer udtrykker hopierne de fænomener, vi kalder tid og rum, og således lever hopierne med en ganske særlig og vedvarende model af universet.
\end{abstract}

Derpå følger en længere redegørelse for hopisprogets to påståede kosmiske grundformer, nemlig Det Objektive og Det Subjektive:

Det objektive er det håndgribelige. Det omfatter alt, som er åbenlyst for vore sanser. Det historiske og det fysiske tilhører således det objektive, med andre ord, den klart håndgribelige verden. Her er der ingen forskel på fortid og nutid. I stedet er der tale om en dimension, en slags uendeligt udvidet nu, hvor alt, som er sket, vedvarende er med i oplevelsen af tilværelsen. Det er en oplevelse, som kort sagt kan kaldes varighed eller fortvoeren .... Hvis vi siger, at vor fortid og nutid hos hopierne dækkes af Det Objektive, så hører det traditionelt europæiske fremtidsbegreb ind under Det Subjektive, hopisprogets anden grundform. Men i Det Subjektive findes ikke kun det, vi kalder fremtid, men også alt det, som kan henføres til emotionelle og sjælelige processer. I den forstand kan vi godt sige, at alle følelser og tanker hos hopierne er en slags fremtid. Et frapperende eksempel herpå er, at et minde, eller det at mindes, hører til fremtiden, eller rettere sagt det subjektive plan, hvor det vel at mærke stræber efter på ny at manifestere sig, det vil sige blive en del af det objektive, med andre ord virkeligheden. Hvad med andre ord betyder, at et minde kan laves om, kan ændres. Alt indre er på den måde en tidsmaskine, en fremtid for hopien, som kan ændre fortiden ... Det fremtidige er altså ikke skilt fra hopien, men er lige fra begyndelsen altid til stede hos hende. Gennem sin bestandige opmærksomhed, ved hopien, at hun kan påvirke og rette det til, eller ændre det, som hun vil virkeliggøre, for eksempel i fortiden. Den er med andre ord aldrig forbi, fortiden. Den fin- 
des i fremtiden.

Lundbye berører også Paulus som den, der i vores kultur kommer fænomenet nærmest. Ifølge Lundbye "taler [Paulus] om fortiden, der kaster sin skygge bagud og på den måde kan påvirke nutidsmennesket.” Jeg skal ikke gøre mig klog på Paulus; men jeg kan sige med ren samvittighed, at Lundbye vrøvler i den grad om hopisprog og hopimentalitet. Jeg syntes ikke, at talen skulle stå uimodsagt og skrev til Weekendavisens redaktør Anne Knudsen:

\begin{abstract}
Jeg undrer mig over at I har trykt Vagn Lundbyes takketale. Den er fyldt med så megen indianer-romantik at det er en hån mod etnografer og andre, som mig selv, som har udført feltarbejde hos hopi-indianerne, lært deres sprog og ellers har kendt dem i mange år. Der er ikke et eneste udsagn om hopierne i hans tale som er sandt - desværre er det et genopkog af nogle af de værste myter om hopierne, som romanforfattere og andre har promoveret i over 50 år.... [Jeg bliver nødt til at skrive] et eller andet, ellers kan vi lige så godt opgive at drive kulturforskning - for, hvem gider at høre på os, når Lundbye får så megen spalteplads til så uendelig lidt? (e-mail af den 2.12.02)
\end{abstract}

Anne Knudsen skrev tilbage, at man trykte talen, fordi det "nu engang var den tale, han holdt, da han fik den betydningsfulde pris - som det jo ikke var os, der gav ham. Det er sådan, Lundbye faktisk mener, og det er vi jo ikke i nogen position til at lave om på. Men Lundbye må, ligesom andre, der ytrer sig offentligt, være parat til at blive sagt imod." Jeg skrev derpå en offentlig kritik, der fik overskriften "Lundbyes vrøvl”, og hvor jeg fremhævede, at det var en skandale, at Lundbye kunne høste anerkendelse for en sådan gang selvhøjtideligt indianerromantik (Geertz 2002b). Der er tale om intet mindre end kulturel misrepræsentation, forvrængning af andre folks kulturelle værdier og verdener.

Mit indlæg vakte en smule opsigt - også i hjemlige indianerkredse, der lod artiklen genoptrykke i den Dansk-Indianske Forenings blad Hau Kola (Geertz 2003b). Det var utroligt, at Lundbye tillod sig at hævde, at han havde gjort alle disse opdagelser, mens han boede hos hopierne i 1974, al den stund han intet kendskab har til hopi-sproget. Det er da også tankevækkende, at der er andre, som før Lundbye har hævdet at have 'opdaget' dette om hopi-sproget, og som har fremført opdagelsen som sprogvidenskabelige og filosofiske hypoteser. Det drejer sig om den berømte 'Sapir-Whorf-hypotese'. Det var Benjamin Lee Whorf, der fremførte de ideer i 1930erne, ${ }^{1}$ som Lundbye hævdede at have opdaget. At Whorfs påstande om hopi-sproget siden er blevet godt og grundigt modbevist af blandt andre sprogforskeren Ekkehart Malotki, har Lundbye desværre ikke opdaget. Og det har de andre fantaster, som regelmæssigt 'opdager' dette om hopisproget, heller ikke. Jeg har for nogle år siden i en stille stund optalt, hvor mange sætninger om tid og rum, Malotki har kunnet få ud af sine hopi-informanter. Han har udgi-

${ }^{1}$ Se Whorfs essays i Carroll 1956. 
vet resultaterne i to omfangsrige værker om henholdsvis hopi-tid og hopi-rum (1979, 1983), der viser, at hopi-sproget har en overflod af tids- og rumbegreber, grammatiske kategorier osv. Det blev til 3.977 sætninger.

Historien bag denne skrøne om hopi-sproget er et kapitel for sig, som jeg ikke vil komme ind på her. Lad mig her nøjes med at konstatere, at min første konfrontation med fænomenet var en analyse, jeg skrev i 1983 af Frank Waters' Book of the Hopi fra 1963 (Geertz 1983, 1987, 1990). Bogen, der blev promoveret som 'den sande hopibibel', var en blanding af jungianisme, ufo-dyrkelse, dårlig etnografi og hippiereligiøsitet. Den blev faktisk hippiernes bibel og var en af årsagerne til, at hopi-land gennem 1960'erne blev oversvømmet af naive, mystiske og mærkelige hippier. Jeg har i kapitlet "Hippie-sinom (Hippie People) and the Crisis of Meaning" skrevet om dette i min disputats (Geertz 1992a, 331ff). Det var et mareridt for hopierne, som de aldrig har glemt, og som førte til, at hopierne blev mere og mere fjendtligt indstillet over for hvide besøgende. Desværre havde fagfolk fra andre discipliner svært ved at gennemskue Waters bog, og man diskuterede dens fortræffeligheder, som om den var et alternativ til almindelig, kedelig, aristotelisk etnografi. Lidt på samme måde som man drøftede Carlos Castanedas første bog om den fantastiske Don Juan, som han hævdede at have mødt på etnografisk feltarbejde hos yaqui-indianerne i Mexico. Denne Don Juan kunne forvandle sig til kraftdyr, springe over bjerge, bekæmpe åndelige uhyrer, udføre bilokation og den slags, og han skulle angivelig have lært Carlos Castaneda disse egenskaber. Castanedas første bog The Teachings of Don Juan (1968), der påstås at være en bearbejdet udgave af hans ph.d.-afhandling, og som tydeligt var ren fiktion, blev af dele af det amerikansk etnografiske establishment udråbt som frisk nytænkning, hvor etnografens egen felterfaringer gav adgang til en mere autentisk etnografi. Bogen udkom to år inden den postmoderne bølge ramte etnografien.

Richard de Mille (1976, 1980) har skrevet en meget underholdende beskrivelse af denne skandale, som bl.a. endte med en paneldebat ved American Anthropological Associations årsmøde, hvor bogen, ph.d.-afhandlingen, hans ph.d.-vejledere osv. blev diskuteret (jf. Noel 1976) Om Castenada skrev bladet New Age: "He may be lying, but what he says is true" (citeret i de Mille 1980, 39). Dette er trods alt et udsagn fra et populært blad, men det opsigtsvækkende for os er, at antropologer som Mary Douglas synes at antropologien bør tage Castenadas publikationer alvorligt (Douglas 1980). Men som de Mille skrev, denne type litteratur tilslører forholdet mellem to sandhedskriterier nemlig validitet og autenticitet:

Since most people, including anthropologists, care more about validity (which is theoretical and therefore interesting) than about authenticity (which is a rather boring practical condition for obtaining valid information), they tend to take authenticity for granted whenever they read a report whose content seems valid to them. I believe this is exactly the error Mary Douglas fell into. (de Mille 1980, 45)

Waters’ bog hører til tidsånden i den amerikanske etnografi, hvor fiktion italesættes som 
autentisk eksperientiel fortælling. Min kritik af Waters bog blev startskuddet på en langvarig, faglig forvandling fra religionshistorisk kulturrelativist til religionsvidenskabelig samfundskritiker. Det var validitets- og autenticitetsspørgsmål som lå mig mest på sinde. I begyndelsen var min kritik rettet mod romanforfattere og fabulanter, der udgav sig for at være etnografer. Men også fagfæller var efter min mening faldet for de nye tendenser. Min debat med religionsvidenskabsmanden John Loftin, som samtidig var aktivist og advokat for indianske retssager, og som i 1991 udgav bogen Religion and Hopi Life in the Twentieth Century var udtryk for denne tendens. Her viste det sig at hans bog bestod bl.a. af et genopkog af Whorfs fejlagtige påstande om hopi-sproget og en stor portion New Age-spiritualitet (Geertz 1992b; 1993). Jeg førte en tilsvarende debat med en tysk litteraturforsker ved navn Rudolf Kaiser, der i 1989 udgav en pseudoetnografisk bog om hopi-indianernes profetiske udsagn (Kaiser 1989; 1990; 1991; Geertz 1991a). En anden skandale, der skulle optrevles, var Høvding Seattles påståede tale, som han angiveligt skulle have holdt ved en traktatceremoni i 1855. Talen er et godt eksempel på den indianske miljøetik, som amerikanerne har været så optaget af siden 1970'erne. Talen er et falsum, opdigtet af en professor i medievidenskab i Texas til en film produceret af Southern Baptist Church (Geertz 1992c). Økoindianeren blev skabt af miljøgrupper og kristne organisationer efter filmen blev vist i 1972.

Jeg forsøgte at forstå denne kulturelle galskab ved at undersøge den mentalitetshistoriske baggrund for primitivismen i Europa og Amerika (Geertz 1994; 2000b; 2002a; 2004a). Det er en fascinerende historie om, hvordan man i Vesten har brugt fremmede folkeslag som led i egen selvforståelse som spejlvendte billeder af os selv. Det er et gammelt fænomen, der går tilbage til klassisk tid, men som fik fornyet aktualitet efter opdagelsen af det amerikanske kontinent. Der er tale om en underlig historie, hvor perioder med kulturel selvforagt eller usikkerhed gav anledning til at anskue de fremmede som ideelle alternativer til vor kultur - en form for xenofili -, mens det i perioder præget af selvforherligelse førte til en forståelse af de fremmede som underudviklede mennesker, der udgjorde en trussel mod vore kulturelle værdier - en form for xenofobi.

Min samfundskritik var i flere år fortsat udtryk for kulturrelativisme som var baseret på min utilfredshed med den vestlige kulturs imperialisme og foragt for andre mennesker og kulturer. Jeg var helt og holdent på indianernes side i den henseende og havde ingen betænkeligheder ved at være religionskritisk over for den europæiske og amerikanske imperialismes religioner, katolicismen og protestantismen. New Age var blot udtryk for det samme i forklædning.

Denne holdning kom også til udtryk i en vedvarende fagkritik, hvor jeg bidrog til den postkoloniale, feministiske og postmoderne debat, fx i regi af det amerikanskbritiske tidsskrift Religion (Geertz 1991b; 1995a; 1995b; 1997c; 2000a; 2001). Men det var indlysende, at denne kritik - udført primært af etniske minoriteter og kvindelige feminister - skjulte andre dagsordener, som jeg ikke brød mig om. Det var nemt at gennemskue, hvilke magtfaktorer der var på spil. Men kritikken var alligevel god nok, syntes jeg. Vores videnskabelige undersøgelser var farvet af kolonimagternes værdier og politiske strategier, vort sprog og emnevalg var chauvinistisk, vore teorier var tæt 
forbundet med magtrelationer, som minoriteterne ikke havde indflydelse på, og som de af forskellige grunde, primært sociale og økonomiske, ikke kunne tage del i, etc.

Jeg forsøgte at argumentere for det, jeg kaldte "a no nonsense approach to religion", hvor man forsøger at komme hinsides ideologiske og romantiske opfattelser af de fremmede. Jeg forestillede mig en slags ikonoklastisk pædagogik, hvor man dekonstruerer det eksotiske for derefter at rekonstruere det eksotiske gennem ordentlig etnografiske og religionsvidenskabelige metoder. Samtidig syntes jeg ikke, det var urimeligt, at vi talte med de mennesker, vi undersøgte, som udtryk for en elementær, videnskabelig fordring om redelighed og empirinærhed. Der var, har man siden opdaget, noget, der hedder forskningsetik. Idealet for mig var en rekonstruktion af en videnskabelig konsensus i en pluralistisk verden. Men det var samtidig indlysende, at fagkritikken har sine grænser. Man kunne gå langt over gevind med sin fagkritik. Konferencerne i USA var en lidelse at deltage i. Det var anthro-bashing på alle planer, mest af midaldrende hvide mænd, uanset faglig disciplin. Det var en hård periode at komme igennem. Men tiderne har ændret sig. Også fra indianernes side har man opdaget, at det er en bedre strategi at etablere samarbejde med fornuftige, hvide akademikere. I dag synes jeg, at vi går en spændende og produktiv tid i møde. Der er mange stammer i dag, som byder velkommen til forskere, og som beder om hjælp til at uddanne egne forskere, primært arkæologer og antropologer. Den bog, jeg er i gang med at skrive om nutidige forhold hos indianerne i Nordamerika, er udtryk for dette nye samarbejdsklima.

Jeg forsøgte at formulere en metodisk platform, som ikke længere var kulturrelativistisk, nemlig etno-hermeneutikken (Geertz 1996a; 1998; 1999a; 2003a). Den etnohermeneutiske tilgang var et forsøg på, som jeg har formuleret det forskellige steder, "at lokalisere såvel forskeren selv som de indfødte i hver deres netværk af tekster, traditioner, betydninger og sociale og intellektuelle omstændigheder." (Geertz 1998, 11). Resultatet, hævder jeg, bliver et tredje perspektiv, som transcenderer parternes egne forståelsesrammer. Jeg forestillede mig et redskab på fire niveauer, som jeg ikke skal uddybe i denne sammenhæng (taksonomisk analyseredskab, hermeneutisk redskab, redskab til en hermeneutisk konfrontation og dialogredskab). Det er væsentligt for mig at fastholde den agnostiske platform som et fælles udgangspunkt for dialog mellem os og de folk, vi studerer. Hvis en indianer ønsker at lave akademisk arbejde, skal han eller hun også tilslutte sig de vestlige videnskabelige principper. Hvis vi ønsker at lave et akademisk arbejde om indianere, skal vi lytte til de mennesker, vi studerer, være opmærksom på vores arbejdes etiske implikationer og være tro mod vores videnskabelige principper.

Det sidste skridt på vejen til en fuldvoksen universalisme er min interesse i kognition og psykologi. Det amerikanske uddannelsessystem har en meget høj grad af naturvidenskabelige fag på alle niveauer. Således kan man på amerikanske universiteter vælge at tage $\mathrm{X}$ antal point i naturvidenskabelige fag - det gælder også for humanistiske kandidater. Jeg tog selv kurser i biologi, astronomi og andre fag sammen med arkæologi, sociologi og mit hovedfag, engelsk litteratur. Mens jeg skrev ugentlige essays om Shakespeares skuespil, fordybede jeg mig i det menneskelige endokrinsystem og nervesystem samt stjernernes kemiske sammensætninger. Det giver unægtelig et andet syn på 
engelsk litteratur end man er vant til i Europa. Hjerneforskningen var i 1970, da jeg forlod USA, kun lige begyndt på en på mange måder opsigtsvækkende udvikling (Geertz 1999b; 2004b; 2004c; 2004d; 2005a; 2005c). De vigtigste arkæologiske fund om de tidligste menneskearter var også først begyndt at blive afdækket. I dag er der tale om en helt anden situation. Nye metoder og nye opdagelser synes at bekræfte menneskets enhed. Rent genetisk har man opdaget, at alle uden for Afrika tilhører samme genetiske slægt. Mennesket stammer med andre ord ét sted fra - i Østafrika - hvis slægtslinje har overlevet i vores gener. I Afrika derimod er der tale om en række forskellige genetiske linjer, et sted mellem 8 og 15 forskellige linjer (se bl.a. Sykes 2001; Wells 2002). Hvad det betyder, er i øjeblikket svært at gennemskue; men under alle omstændigheder indebærer det, at alle mennesker har samme biologi og samme tilpasningsevner. De har samme hjernekonstruktion med samme hjernefunktioner. De har desuden en fabelagtig evne til kulturel variation. Deres religioner er lige så variable. Men der er tilsyneladende grundlæggende ensartede forudsætninger. Pascal Boyer hævder, at der kun er 15 grundideer i religionernes verden. Resten er variationer over samme tema (Boyer 2000, 199). Religiøs adfærd og forestillinger bygger på, bruger og domesticerer træk, der er fælles for alle mennesker, som fx social intelligens, moralsk adfærd, normativ adfærd, samhørighed, symbolske verdener etc.

Er jeg universalist? Og står det at være universalist i modsætning til en kulturrelativistisk position? Er jeg skizofren, når jeg underviser i hopi-religion om tirsdagen og religionspsykologi om torsdagen? Er min jagt på sandheden anderledes om tirsdagen, end den er om torsdagen? Jeg mener, at faget ligger midt i spændingsfeltet mellem en kulturrelativistisk partikularisme og en almen menneskelig universalisme. Man kan også formulere problemet i lighed med blandt andre Jeppe Sinding Jensens iagttagelse, at der er tale om to sider af samme sag, nemlig ideografiske og nomotetiske tilgange. Den ene tilgang forudsætter den anden (Jensen 2003, 148f.).

Lad mig afslutningsvis vende tilbage til Vagn Lundbye: dårlig etnografi, ja. Men er vor grundlæggende ærinder så forskellige? Vi er begge samfundskritikere. Vi er også begge kritiske over for visse former for videnskab. Lundbye sagde en gang til mig, at han tager derhen i verden, hvor han bedst kan finde sig selv. Og jeg må konstatere, at han tager mange danskere med sig. Som Troels Kløvedal tager han danskerne på virtuelle rejser, hvor de bliver konfronteret med sig selv, deres værdier og deres historie. Gør jeg det samme? Er det, hvad regeringen mener med videndeling?

Forskellen er vel, at man som forsker forpligter sig på nogle spilleregler og metoder. Man foregiver at være arkitekt. Som religionsforsker rekonstruerer man andres religiøse verdener. Nogle gange er der tale om banaliteter på stylter. Andre gange er der tale om luftkasteller. Enkelte gange rammer man plet, således at både de indfødte og vores kolleger kan genkende det (Geertz 1996b; 1997a; 1997b; 1999b).

Jeg har formuleret mit aktuelle standpunkt i Gyldendals Hvad enhver dansker bør vide, og vil lade et citat herfra være mine afsluttende ord:

For at kunne besvare spørgsmål [om religionens væsen, oprindelser, former, funktioner, 
strukturer og betydninger] må man bo i et samfund, hvor det er tilladt at stille andre spørgsmål end de, religionerne selv tillader. Det kræver, at man har lov til at tvivle på Jesus' eksistens uden at tabe sin stilling eller at man kan stille kritiske spørgsmål til Quranen uden at få udstedt en fatwa mod en. Det kræver m.a.o. en sekulær sammenhæng, hvor religiøse dagsordener forbliver religiøse og ikke får lov til at bestemme over samfundets, politikkens og kulturens muligheder og spørgehorisonter. Men fordi religioner konkurrerer ikke alene indbyrdes, men også - og måske mest - med den sekulære sammenhæng, vi befinder os i, er det bydende nødvendigt at der stilles alternativer op til religiøse påstande og at der udføres seriøse undersøgelser af de menneskelige sider og konsekvenser af religion. Mange vil kalde den videnskabelig undersøgelse af religion for "reduktionistisk", dvs. at man ikke ukritisk tager religiøse udsagn for givet eller sande eller enestående, men at man prøver at finde ud af, om der er andre ting på spil, f.eks. autoritet, socialt pres, psykologisk manipulation eller sågar neurobiologiske processer. Debatten i USA om "creationisme" og den systematiske kritik af udviklingslæren er et godt eksempel på, hvor hedt det kan gå til, og hvor manipulative religioner kan blive i sekulære samfund. Selvom religioner kan levere forklaringer på verdens ondskab, tilbyde kærlige og bekræftende tilhørsforhold, give anledning til sublime oplevelser og berolige en tynget samvittighed, medfører det altid menneskelige omkostninger. Det koster at opnå sikre overbevisninger i en ellers usikker og farlig verden. (Geertz 2005b, 464)

\section{Litteratur}

BOYER, PASCAL

2000 "Functional Origins of Religious Concepts: Ontological and Strategic Selection in Evolved Minds", The Journal of the Royal Anthropological Institute 6 (2), 195-214.

CARroll, John B., ED.

1956 Language, Thought, and Reality: Selected Writings of Benjamin Lee Whorf, The M.I.T. Press, Cambridge.

CAstaneda, Carlos

1968 The Teachings of Don Juan: A Yaqui Way of Knowledge, The University of California Press, Los Angeles.

DE MiLle, RichaRd

1976 Castaneda's Journey: The Power and the Allegory, Capra Press, Santa Barbara.

DE Mille, RichaRd, ED.

1980 The Don Juan Papers: Further Controversies, Wadsworth Publishing Company, Belmont, rev. udg. 1990.

DOUGLAS, MARY

1980 "The Authenticity of Castaneda", i R. de Mille, ed., The Don Juan Papers: Further Controversies, Wadsworth Publishing Company, Belmont, rev. udg. 1990, 25-31.

GEERTZ, ARMin W.

1983 "Book of the Hopi: the Hopi’s Book?" Anthropos. International Review of Ethnology and Linguistics 78 (3/4), 547-556.

1987 “Hopi-Forschung, literarische Gattungen und Frank Waters' Das Buch der Hopi”, i Hans Peter Duerr, ed., Authentizität und Betrug in der Ethnologie, Suhrkamp, Frankfurt a.M., 111-136. 
1990 "Reflections on the Study of Hopi Indian Mythology", in Christopher Vecsey, ed., Religion in Native North America, University of Idaho Press, Moscow, 119-135.

1991a "Hopi Prophecies Revisited: A Critique of Rudolf Kaiser", Anthropos. International Review of Ethnology and Linguistics 86 (1-3), 199-204.

1991b "Native American Art and the Problem of the Other: An Introduction to the Issues", European Review of Native American Studies 5 (2), 1-5.

1992a The Invention of Prophecy: Continuity and Meaning in Hopi Indian Religion, Knebel, Brunbakke Publications 1992, forkortet og rev. udg. University of California Press, Berkeley, 1994.

1992b "The Archaic Ontology of the Hopi Indians. On John Loftin's Interpretation of Hopi Religion", Anthropos. International Review of Ethnology and Linguistics 87, 537-543.

1992c “Høvding Seattle: nutidens håb, urtidens profet?" Religion 3, 6-19.

1993 "Archaic Ontology and White Shamanism: A Review Article", Religion. An International Journal 23 (4), 369-372.

1994 "Religionsvidenskabens primitivitetsopfattelse: Kritik og nyere erkendelser", Religionsvidenskabeligt tidsskrift 25, 3-39.

1995a "On Reciprocity and Mutual Reflection in the Study of Native American Religions", Religion. An International Journal 24 (1), 1-7.

1995b "Critical Reflections on the Postmodern Study of Religion", Religion. An International Journal 24 (1), 16-22.

1996a "Contemporary Problems in the Study of Native North American Religions with Special Reference to the Hopi", The American Indian Quarterly 20 (3\&4), 393-414, (repr. i: Lee Irwin, ed. To Hear the Eagles Cry: Contemporary Themes in Native American Spirituality, University of Nebraska Press, Norman 1997).

1996 b "Begrebet religion endnu engang - et deduktivt forsøg", Chaos. Dansk-Norsk tidsskrift for religionshistoriske studier 26, 109-128.

1997a "Illumination, korrespondens og religion. Et svar til Per Bilde", Chaos. Dansk-Norsk Tidsskrift for Religionshistoriske Studier 28, 145-154.

1997b "Theory, Definition, and Typology: Reflections on Generalities and Unrepresentative Realism", Temenos. Studies in Comparative Religion Presented by Scholars in Denmark, Finland, Norway and Sweden, 33, 29-47.

1997c "Den globale udfordring af religionsvidenskabens metodologi”, i: Lene Buck, Margrethe Haraldsdatter, Anneline Juul, Charlotte Schönbeck, Oluf Schönbeck, ed., Idealer i religion og religionsforskning, Museum Tusculanums Forlag, København, 183-209.

1998 "Fortolkning og samskabelse. En etnohermeneutisk tilgang til hopi-indianernes religion", Religion. Tidsskrift for Religionslcererforeningen for Gymnasiet og HF 4, 10-25.

1999a "Ethnohermeneutics in a Postmodern World", in Tore Ahlbäck, ed., Approaching Religion, Part I: Based on Papers Read at the Symposium on Methodology in the Study of Religions Held at Abo, Finland, on the 4th-7th August 1997, The Donner Institute for Research in Religious and Cultural History, Åbo \& Almqvist \& Wiksell International: Stockholm, 73-86.

1999b "Definition as Analytical Strategy in the Study of Religion", Historical Reflections/Reflexions Historiques 25 (3), 445-475.

2000a "Global Perspectives on Methodology in the Study of Religion", i Armin W. Geertz, Russell T. McCutcheon, assisteret af Scott S. Elliott, eds., Perspectives on Method and Theory in the Study of Religion: Adjunct Proceedings of the XVIIth Congress of the International Association for the History of Religions, Mexico City 1995, E. J. Brill, Leiden, 49-73.

2000b "Oprindelige folks religioner: Indledning", i Mikael Rothstein, ed., Politikens håndbog $i$ Verdens religioner, Politikens Forlag, København, 322-329. 
2001 "Komparative strategier hos Edv. Lehmann. Et tilbageblik på den tidlige religionshistorie", in Erik Reenberg Sand \& Jørgen Podemann Sørensen, eds., Edvard Lehmann og religionshistorien - Et symposium ved fagets 100-års jubilaeum i Danmark, Institut for Religionshistorie, Københavns Universitet, København, 39-48.

2002a “De oprindelige folk - naturfolk eller kulturfolk?”, Religion. Tidsskrift for Religionslaererforeningen for Gymnasiet og $H F$ 1, februar, 8-32.

2002b "Lundbyes vrøvl", Weekendavisen 6. - 12. december, 11.

2003a "Ethnohermeneutics and Worldview Analysis in the Study of Hopi Indian Religion", Numen 50 (3), 309-348.

2003 b "Rumtid og indianerromantik", Hau Kola. Medlemsblad for Dansk-indiansk Forening 17 (1), 4-6.

2004a "Can We Move Beyond Primitivism? On Recovering the Indigenes of Indigenous Religions in the Academic Study of Religion", i Jacob Olupona, ed., Beyond "Primitivism": Indigenous Religious Traditions and Modernity, Routledge, New York and London, 3770 .

$2004 b$ "What is religion for? Theoretical perspectives", i Joseph A. Bulbulia and Paul Morris, eds., What Is Religion for?, Victoria University of Wellington, Wellington, 1-12.

2004c "Cognitive Approaches to the Study of Religion", i Peter Antes, Armin W. Geertz \& Randi Warne, eds., New Approaches in the Study of Religion, Mouton de Gruyter, Berlin, Volume 2: Textual, Comparative, Sociological, and Cognitive Approaches, 347-399.

2004d "Sladder som religiøs fortælling - kognitive og socialpsykologiske betragtninger", i Armin W. Geertz, Hans J. Lundager Jensen \& Jens Peter Schjødt, eds., Det brede og det skarpe - Religionsvidenskabelige studier. En gave til Per Bilde på 65-årsdagen, Forlaget Anis, København, 47-64.

2005a "Fra neurale netværk til sakrale kongedømmer: religionsvidenskabens komparative projekt", i: Joel Haviv, Anders Lisdorf \& Peter Weiss Poulsen, eds., Sammenligning i religionsvidenskaben, særnummer af tidsskriftet Chaos, København, Museum Tusculanums Forlag, 55-78.

2005b "Religion og mytologi. De store spørgsmål”, i: Adam Hyllested, Dorrit Löb, Gert Posselt \& Lene Vistrup, eds., Hvad enhver dansker bør vide, Gyldendal Leksikon, København, 462-469.

2005c "Om religion og kognition - en forskningshistorisk og tematisk introduktion", Religionsvidenskabeligt tidsskrift 46, 5-26.

JENSEN, JEPPE SINDING

2003 The Study of Religion in a New Key: Theoretical and Philosophical Soundings in the Comparative and General Study of Religion, Aarhus University Press, Århus.

KAISER, RUDOLF

1989 Die Stimme des Großen Geistes: Prophezeiungen und Endzeiterwartungen der HopiIndianer, Kösel-Verlag, München.

1990 "Prophecies and Eschatological (Millennial) Traditions of the Hopi Indians in Arizona", Anthropos. International Review of Ethnology and Linguistics 85, 65-71.

1991 The Voice of the Great Spirit: Prophecies of the Hopi Indians, Shambhala, Los Angeles.

LOFTIN, JoHn D.

1991 Religion and Hopi Life in the Twentieth Century, Indiana University Press, Bloomington.

LUNDBYE, VAGN

2002 "Om tid", Weekendavisen 29. november - 5. december, 12.

MALOTKI, EKKEHART

1979 Hopi-Raum: Eine sprachwissenschaftliche Analyse der Raumvorstellungen in der HopiSprache, Gunter Narr Verlag, Tübingen. 
1983 Hopi Time: A Linguistic Analysis of the Temporal Concepts in the Hopi Language, Mouton Publishers, Berlin.

NoEl, DANiel C., ED.

1976 Seeing Castaneda: Reactions to the "Don Juan" Writings of Carlos Castaneda, Capricorn Books, New York.

SYKES, BRYAN

2001 The Seven Daughters of Eve, W. W. Norton \& Company, Inc., New York.

WATERS, FRANK

1963 Book of the Hopi, The Viking Press, New York.

WELLS, SPENCER

2002 The Journey of Man: A Genetic Odyssey, Princeton University Press, Princeton \& Oxford.

Armin W. Geertz

Professor, dr.phil.

Afdeling for Religionsvidenskab

Aarhus Universitet 